\title{
El malestar en la psicopatología contemporánea
}

\author{
Luciane Loss Jardim* \\ Universidade Estadual de Campinas, Campinas, SP, Brasil \\ Faculdade de Jaguariúna,. Jaguariúna, SP, Brasil
}

\begin{abstract}
Resumen: El objetivo del artículo fue presentar una lectura, orientada por el psicoanálisis, acerca del malestar en el campo de la psicopatología contemporánea. Hace mucho tiempo que la psiquiatría mantenía el sueño de encontrar los marcadores biológicos para explicar los comportamientos humanos y sus desvíos, y ahora ganó nueva inversión a partir del nuevo plan estratégico del Instituto Nacional de Salud Mental (NIMH, su sigla en inglés), que si por un lado incentiva el progreso de la ciencia, por otro, plantea un reduccionismo organicista. Sin tomar la posición opuesta, es decir, la de un puro psicologismo de los trastornos mentales o una negación de los factores biológicos en la psicopatología, en este trabajo se plantea una discusión acerca del tema señalando una posición clínica, ética y epistemológica en el abordaje del sufrimiento psíquico. Se concluyó con una aportación del psicoanálisis para el campo de la psicopatología y la práctica en salud mental.
\end{abstract}

Palabras clave: psicopatología, psiquiatría, psicoanálisis y organicismo.

\section{Introducción}

"Mi enfermedad es física no mental", decía Pablo en la enfermería psiquiátrica del hospital universitario donde estaba internado por el recrudecimiento de su cuadro clínico de esquizofrenia paranoide. Tenía un delirio hipocondríaco sistematizado con alucinaciones verbales y trastornos de lenguaje que incluían neologismos. Desde su construcción delirante, exigía una revisión médica, necesitaba una junta médica con varios especialistas, gastroenterólogo, urólogo, neurólogo y dermatólogo, pues sufría de un deterioro de su cuerpo. Por lo tanto, tenía una certeza delirante acerca de que su malestar era físico.

El origen del delirio de Pablo parece ser compartido por una parte significativa de la comunidad científica en lo que concierne a la psicopatología. Es decir, los trastornos mentales son estrictamente orgánicos o el mental es algo que se puede reducir al sustrato biológico. Sin tomar la posición opuesta, es decir, la de un puro psicologismo de los trastornos mentales o una negación de los factores biológicos en la psicopatología, vamos a presentar una lectura acerca del malestar en el campo de la psicopatología contemporánea. Sin dudas, nuestra intención no es agotar el tema o plantear una solución definitiva para el malestar en este campo, sino apuntar algunas direcciones para mitigar el sufrimiento.

Dominar la naturaleza no es la única, como dijo Freud (1929/1974), sino una de las precondiciones para la felicidad humana, y en este sentido hay un gran esfuerzo de la ciencia en sujetar lo real. El reto de la psiquiatría moderna está en encontrar los marcadores biológicos para explicar los comportamientos humanos y sus desvíos. La integración entre la neurociencias y psicopatología es

* Dirección para correspondencia: lulossjardim@uol.com.br el nuevo plan estratégico del Instituto Nacional de Salud Mental (NIMH, su sigla en inglés), que es el organismo de inversión más importante del mundo para la investigación en salud mental. Su objetivo es desarrollar la investigación de nuevas formas de clasificar los trastornos mentales con base en dimensiones de conducta observable y medidas neurobiológicas.

La implementación de este objetivo está a cargo del proyecto Criterios de Dominio de Investigación (RDoC), el cual fue "desarrollado para explorar formas de incorporar métodos tales como genética, neuroimágenes y ciencia cognitiva en futuros esquemas diagnósticos basados en dimensiones conductuales y sistemas neurales" (Cuthbert, 2014, p. 28). El proyecto no tiene como propuesta priorizar la fenomenología descriptiva del Manual Diagnóstico y Estadístico de los Trastornos Mentales (DSM, su sigla en inglés), inclusive se exoneró la edición recién lanzada, el DSM-V. Según Cuthbert (2014), en dicho manual no se muestra casi ninguna influencia de los avances notables en nuevas tecnologías y conocimientos sustanciales en neurociencia y ciencia conductual desde que se publicó el DSM-IV en 1994.

Apenas dos semanas antes de presentarse el DSM-V, el NIMH anunciaba que retiraba su apoyo para esta nueva edición. En un golpe humillante para la Asociación Americana de Psiquiatría (APA, su sigla en inglés), el director del NIMH, Thomas Insel dejó claro que la agencia de proyectos de investigación de fondos ya no que se basa exclusivamente en los criterios del DSM. A partir de entonces, el instituto, que había subvencionado las ediciones anteriores del manual, declaraba que en delante su apoyo sería "para reorientar su investigación fuera de las categorías del DSM" (n.p.). "La debilidad" del manual, explicó Insel (2013) en un comunicado agudamente redactado, "es su falta de validez" (n.p.). "A diferencia de nuestras 
definiciones de la enfermedad isquémica del corazón, el linfoma o el SIDA, los diagnósticos del DSM se basan en un consenso acerca de los clústeres de síntomas clínicos, no cualquier medida objetiva de laboratorio." (Insel, 2013, n.p.)

\section{El malestar en la clínica psicopatológica}

Ante lo expuesto, cabe plantear la pregunta: ¿Haremos el diagnóstico de esquizofrenia, por ejemplo, a partir del examen de la sangre o a través de las imágenes cerebrales? ¿Es posible someter todo el caleidoscopio sintomático de la esquizofrenia, por ejemplo, a las medidas del laboratorio?

Esta es la creencia de muchos científicos. Pero todavía no lo es de todos. El reduccionismo organicista ya no es una certeza en la causalidad, incluso en la neurociencia. Kandel, premio Nobel de Medicina en el año 2000, que desarrolló investigaciones acerca de las funciones sinápticas en el campo de la memoria y de la neurotransmisión, descubrió lo que se llama de neuroplasticidad cerebral, que es la selectividad del crecimiento neural de acuerdo con el tipo de estimulación que recibe el niño, lo cual permite inferir que el ambiente -y ahí podemos considerar el factor humano- es estructurante de los procesos psíquicos y organizadora de los procesos cerebrales humanos. (Jerusalinsky, \& Laznick, 2011)

Todavía la práctica clínica sostenida a partir del DSM-V propone un discurso que tiene una estructura científica acerca del sufrimiento psíquico humano. La APA a medida que postuló una clasificación de los trastornos mentales sostenida en una metodología esencialmente descriptiva e ateórica de los síntomas y comportamientos que se puede observar, definió una posición clínica, ética e epistemológica en el abordaje del sufrimiento psíquico de los seres humanos.

El DSM-V es una herramienta pragmática y eficaz para ubicar al enfermo en una clasificación, incluso cuando -y eso ocurre con alguna frecuencia- otro clínico o él mismo en otro momento elija otra división del manual para el paciente. En esta medida, la tarea terapéutica puede ser simplificada, pues cuando se logra saber a cuál clasificación del manual corresponde al paciente, se puede elegir el tratamiento correspondiente, tanto el psicoterapéutico como el farmacológico. Es indubitable que el sistema clasificatorio del DSM-V también es un auxiliar excelente para la tarea estadística. Por último, y no menos importante, el médico detiene el conocimiento acerca del trastorno y la solución para el problema. En la psiquiatría clínica contemporánea es invariablemente la psicofarmacología que ha dominado la práctica a lo largo de las últimas décadas.

Nada más de acuerdo con la posición epistemológica de la ciencia médica a partir del siglo XIX, que consolidó su conocimiento "bajo los presupuestos de una base positivista; desde este modelo del conocimiento, el cuerpo se entiende como un organismo que funciona, enferma y se cura en base a una causa orgánica" (Rojas Hernandez, \&
Loss Jardim, 2007, p. 7). Argumento sobre el cual se construyó y sigue se construyendo la psiquiatría.

Según Banzato (2009), la pretensión de neutralidad al respecto de la etiología de los trastornos se configuran como sistema pragmático y una concepción naturalista de la enfermedad. Las limitaciones de la clasificación actual son cada vez más evidentes en lo que concierne a la práctica clínica en psiquiatría y en salud mental (Banzato, 2004). Por lo tanto, la concepción naturalista que obtiene su esquema a partir de las clasificaciones del manual produce un empobrecimiento de la clínica en psicopatología, y muchas veces genera un malestar en la clínica en lo que concierne a los proyectos terapéuticos para los pacientes, por el reduccionismo al empirismo del comportamiento.

Según Rojas Hernandez e Loss Jardim (2007),

el discurso médico se fundamenta en una posición que puede explicarse de manera muy directa, sea de origen orgánica o psíquica, la afección le llega al enfermo desde afuera y por lo tanto, la curación deberá venir también desde afuera. El sujeto es puesto en el lugar de objeto-cuerpo-depositario de una afección y de un saber sobre su afección que lo dejan, por lo tanto, ajeno a lo que le pasa, y también ajeno a una posible solución. En el fondo es el mismo modelo explicativo de la posesión demoníaca, algo entra en el poseso, y la solución es sacar o exterminar eso ajeno que lo posee. (p. 9, cursivas mías)

A su vez el psicoanálisis trata, justamente, de encontrar los propios demonios de los sujetos, es decir, hace que el sujeto se responsabilice por su afección, y puede, conjuntamente con el psicoanalista, buscar la curación en el proceso dialéctico del análisis. Al respecto del trabajo del analista dijo Lacan (1958/1998) "él empieza por introducir al paciente a una primera localización de su posición en lo real, mismo que eso acentúe una precipitación -no hesitamos en decir una sistematización de los síntomas" (p. 602), y señala que dicha ciencia no trata de adaptarse el sujeto a sus síntomas, sino de mostrar su participación en la fabricación de los mismos.

Sin embargo, no se trata de criticar el discurso médico que para poder operar "necesita disecar el cuerpo dentro de los cañones de la observación científica por medio de una metodología que puede y requiere excluir el sujeto, porque no puede tomarlo en cuenta en tanto deseante en el proceso de padecimiento" (Rojas Hernandez, \& Loss Jardim, 2007, p. 9). La medicina psiquiátrica sigue el mismo método de la ciencia, buscando los patrones de comportamiento a través de la observación y descripción de la fenomenología. Sin embargo, no son suficientes para la medicina del comportamiento la observación y descripción de los mismos, pues su anhelo es el de transformar la psicopatología en un puro campo de expresión biológica. Al criticar el sistema de diagnóstico de los trastornos mentales a partir del DSM dijo Insel (2013) "los pacientes con trastornos mentales se merecen algo mejor”. (n.p.) 
Es incontestable que el progreso de la ciencia es mejor para la humanidad. Sin embargo, el mismo progreso tiene tribulaciones, como las pastillas y sus efectos colaterales. La ciencia intenta combatir los males del hombre, y a la vez produce otros. Es el mismo caso lo que ocurre con el reduccionismo de la psicopatología a lo biológico, y con la exclusión del sujeto de su campo. La exclusión del sujeto del inconsciente sobreviene la propia constitución del discurso de la ciencia, supresión que funda, a la vez, el propio campo del psicoanálisis, que ocupa de esto que dicha ciencia desecha.

Por lo tanto, lo mejor para nosotros es que la ciencia siga avanzando en la dirección de la biología de los trastornos mentales, no hay otro camino que no sea el diagnóstico basado en la fisiología, los demás se apartan de la propuesta científica y racional de concebir la realidad material. Esta lógicamente es la nueva orientación del NIMH, que muestra que la inversión deberá ser puesta en las investigaciones biológicas del comportamiento humano.

En este sentido, la clasificación nosográfica del DSM-V ya no sostiene el avance de la ciencia en el campo de la psicopatología, pues a pesar de proporcionar un lenguaje común para describirla fue caracterizada por Insel (2013) como "un conjunto de etiquetas y la definición de cada uno" (n.p.), que no tiene un sustrato orgánico correspondiente. Por lo tanto, la propuesta y la inversión del NIMH serán en datos de investigación emergente, y no en las actuales categorías basadas en síntomas, es decir, en la genética, neuroimágenes, fisiología y cognición. El cuerpo humano sigue siendo disecado, sostenido por la más alta tecnología existente, y hay muchas promesas acerca de las alteraciones neurológicas, químicas y anatómicas sujetados a los trastornos mentales.

Según Zorzanelli, Dalgalrrondo y Banzato (2014), estas declaraciones de desecho del sistema DSM por el NIMH todavía crearon un gran malestar en la comunidad, principalmente en los pacientes, lo que se calmó con otra declaración en conjunta de los representantes del NIMH y de la APA de que el DSM y la Clasificación Internacional de Enfermedades (CID) aún siguen siendo las mejores informaciones disponibles en relación al diagnóstico clínico $\mathrm{y}$ al tratamiento de los trastornos mentales. En el dictamen de los autores, el DSM pasó de icono de la psiquiatría científica a una herramienta provisoria, que tiene el inconveniente de obstruir el desarrollo científico.

No obstante, la propuesta de una psicopatología biológica es un sueño mantenido hace mucho tiempo por la psiquiatría, hija ilegítima de la medicina, puesto que no logró aplicar en su campo el método anatómico-clínico que detalla una enfermedad para el saber médico.

Una enfermedad tiene una sintomatología, un sustrato anatómico-clínico y una etiología. En 1822, Bayle formalizó el cuadro de la parálisis general progresiva a partir de una sintomatología psiquiátrica evidente, un sustrato anatómico, la aracnoiditis crónica del cerebro y un agente etiológico, en el caso, el treponema de la sífilis. Así, dio lugar al origen de la psiquiatría biológica en Francia, y a partir de ahí fue el paradigma ideal para la investigación y el proyecto teórico y terapéutico para la clínica psiquiátrica. Según Pereira (2009), Bayle siguiendo el método anatómico-clínico, que ya estaba desarrollado en la época, ofreció una descripción precisa del cuadro psicopatológico típico y específico, así como demostró su relación con las inflamaciones crónicas de las meninges. Así, estaban puestos los pilares para una construcción del abordaje biológica de la psicopatología.

El proyecto RDoC del NIMH rescata y subraya la propuesta de una psiquiatría basada en la biología. Como esclarece Zorzanelli, Dalgalarrondo y Banzato (2014), dicho proyecto opera con presupuestos más explícitos que el sistema DSM: "Las cartas están en la mesa, y es evidente su apuesta en la patofisiología" (p. 331). El objetivo del $\mathrm{RDoC}$ sería el de ofrecer a la medicina psiquiátrica una medicina de precisión, teniendo como modelo el diagnóstico y tratamiento individualizado del cáncer, comparación recurrente en la literatura psiquiátrica en la actualidad. Los psiquiatras tendrían que hacer su trabajo como lo hacen los oncólogos, es decir, a partir de marcadores biológicos.

Sin embargo, aunque tengamos factores biológicos vinculados a los trastornos mentales, la psicopatología puede ser comprendida apenas "en términos de pérdida de la regulación de las operaciones básicas del cerebro". (Cuthbert, 2014, p. 30)

El editor general de la revista World Psychiatry en el editorial del año 2014, Mario Maj señaló lo bien fundado de la proposición neurobiológica del proyecto $\mathrm{RDoC}$ propuesto por el NIMH. En su argumentación dijo que los delirios, por ejemplo, tienen hoy en la psiquiatría varios elementos de la definición cuestionados, como la cuestión de "creencias falsas", que están basadas en una "inferencia incorrecta", y que esta inferencia siempre considera la "realidad externa" al menos en la esquizofrenia. Por lo tanto, objeta que: "Acaso lo que puede explicarse en términos neurobiológicos no sea las afirmaciones metafóricas del paciente sino las experiencias patológicas básicas que trata de comunicar a través de esas aseveraciones. Tal vez esté justificada una exploración más profunda de esas experiencias" (Maj, 2014, p. 2). Justificadísima, pues ¿no somos hechos de materia orgánica?

\section{Algunas direcciones para mitigar el sufrimiento desde el psicoanálisis}

Por otro lado, no solamente hechos de lo que se puede llamar de materia o de la estructura del cerebro, ya que sus manifestaciones surgen en otro lugar, en las "afirmaciones metafóricas del paciente" como dijo Maj. Es decir, que el fenómeno de la psicosis surge en el registro del habla, del lenguaje.

Entonces, planteamos la cuestión: ¿Qué es el habla? ¿La esquizofrénica habla o no? "Hablar antes de más nada es hablar a los otros" (Lacan, 1955-1956/1988, p. 47). Por lo tanto, la palabra empeña el otro. La unidad de la palabra hablada es fundadora de la posición de los dos sujetos. El lenguaje 
es estructurante de la posición del sujeto y la principal función de los procesos psíquicos y la gran organizadora de los procesos cerebrales humanos. (Jerusalinsky \& Lasnik, 2011)

¿Acaso tomar la palabra de acuerdo con el descubrimiento freudiano no sería un modo de abordar la psicosis, ya que su fenomenología surge justamente en el registro del habla? En el inconsciente están pensamientos estructurados como un lenguaje y que pueden ser descifrados, todavía es un saber que no se puede meter en categorías nosográficas. Es lo que evidencia una escucha psicoanalítica del lenguaje de los pacientes con sus delirios.

Sin embargo, no son todos los clínicos que soportan oír al psicótico, ya señalaba Lacan (1967) en una conferencia acerca del psicoanálisis y la formación del psiquiatra "su presencia en esa posición que es la del psiquiatra, está, lo quiera o no, concernido ¡Está irreductiblemente concernido! . . . si no está concernido, es por algunos procedimientos que se manifiestan cuando mira allí cerca, de manera no refutable, sea uno psicoanalista o no, por el hecho de que él se protege de este concernimiento, si ustedes me permiten. Que él interpone, entre él y el loco, un cierto número de barreras protectoras, que están al alcance de los grandes jefes, él pone, por ejemplo, a otras personas que él mismo, ¿no? Que le suministran informe ....” (p. 10)

Por lo tanto, generalmente la primera reacción del psiquiatra es de enfado. El discurso del delirante es absurdo, incomodo, muchas veces desagregado y desconectado de lo que se está habituado a tener como el orden normal de casualidad. Delante de eso y respaldado por la ciencia, él interpone un cuestionario, y su preocupación en el interrogatorio es encajar todo el rompecabezas. Entonces dice a los enfermos, vamos por partes: ¿Qué día es hoy? ¿Qué edad tienes? ¿Sabes dónde estás? Y sigue el protocolo previamente establecido.

Sin embargo, una buena investigación de las psicosis, según Lacan (1955-1956/1988), podría ser la de dejar hablar el mayor tiempo posible, quizá pueda ser la primera regla de un buen interrogatorio.

Todavía, esta proposición va de encuentro a la clínica psiquiátrica que se especializó en definir una semiología fija, que puede ser ligeramente relativizada por el conjunto de los diferentes diagnósticos, pero arriba de signos previamente determinados como prevalentes patognómicos de determinado cuadro para sujetar la clínica a la medicalización. En este modelo de diagnóstico, se reduce el sujeto a la clasificación a lo mejor no le lleva en consideración.

En esta perspectiva, poco o cuasi nada se sabe acerca del sujeto, de la significación de sus síntomas, de la ubicación de la enfermedad en su vida y de la función además de la orgánica de las medicinas para él. Se reconoce su enfermedad desde la exterioridad. Una crítica hecha por Foucault (1963/2001) que mantiene vigencia hoy, acerca de la medicina moderna que tiene como objeto de estudio la enfermedad o el individuo como cuerpo enfermo. Para que el médico pueda conocer la verdad acerca del hecho patológico debe excluir al enfermo. Este debe ser considerado como un hecho exterior en relación a su enfermedad.
En esta perspectiva, Lacan (1993) señala "es que la ciencia es una ideología de la supresión del sujeto" (p. 62). Es decir, es el ideal epistemológico de liberarse de la contaminación de lo subjetivo. El ideal es la objetivación del mundo, la reducción del sujeto a los sustratos biológicos, como parece ser lo que investiga el proyecto RDoC de NIMH.

Los avances científicos todavía permitieron, por ejemplo, a partir de los años 1950, con el surgimiento de las drogas antipsicóticas, revolucionar el tratamiento de los enfermos. La medicalización de las psicopatologías fue precursora de la reforma asistencial en la salud mental. En 1952, la clorpromazina fue introducida clínicamente en Francia, permitiendo que los psicóticos -principalmente los más graves y agresivos- pudiesen tener un comportamiento mínimamente tolerable para el convivio social. Por lo tanto, con el ingreso de las medicinas antipsicóticas sintéticas en el tratamiento de la psicosis se empezó una progresiva desactivación de los asilos y antiguos hospicios, sustituyéndolos por ambulatorios y servicios más ágiles y menos estigmatizadores.

Por otro lado, las nuevas drogas muy eficaces surgieron como El tratamiento para los enfermos, es decir, casi como la única terapéutica posible para el sufrimiento psíquico. Nos olvidamos de que son medicinas que abaten los síntomas, y no cambian ideas o hacen el duelo por una pérdida sufrida. La tristeza, por ejemplo, es muy mal tolerada en nuestros días, el exceso de medicación a que muchas veces los pacientes están sometidos desvela nuestra inconformidad con el malestar y con el pasaje del tiempo. Hay siempre una busca por el tiempo perdido, no tenemos tiempo para hacer el duelo en la vida moderna.

Siendo así, hagamos una porción mágica en el calderón de los nuevos hechiceros para mantener el buen nivel de serotonina, noradrenalina y dopamina. Lo anterior suena un tanto romántico, siendo más realista podemos decir que este modo de hacer clínica en psicopatología desvela la inmovilidad delante de los intereses económicos de la industria farmacéutica. El psiquiatra pasa a ejercer su función como un distribuidor de psicofármacos.

Por lo tanto, tenemos ahí una cuestión de mercado. Según Costa e Jardim (2003), el propio mercado se encarga de suplir las tiendas con objetos de consumo que prometen la felicidad para quienquiera que quieran consumirlos. El objetivo de cualquier acción farmacológica, por ejemplo, es provocar sentimientos de bienestar completamente independientes del sujeto. Por lo tanto, es habitual que tengamos sentimientos de alegría o tristeza, y estos a la vez tengan suportes bioquímicos. Así, podemos cambiar dichos sentimientos a través de la acción farmacológica. Por esta razón, en nuestros días los hombres pueden producir artificialmente, por acción química, erecciones. Es posible hacer del sujeto un puro mecanismo. Es el ideal de la ciencia, que sigue progresando.

Sin embargo, una cosa es tomar una medicina con la esperanza de que pueda eliminar un síntoma o curar una enfermedad, otra es esperar que eso constituya un sujeto. Pues, él solamente se constituye mientras un ser en falta y 
apartado de cualquier objeto, y que ningún fármaco, por más poderoso que sea, va a reincorporar la pérdida para él.

Así que el psicoanálisis renueva su interés en la palabra del sujeto, y por ello aporta una contribución para la psicopatología y la práctica en salud mental. Tomando el camino de la transferencia, pues los fenómenos transferenciales existen en cualquier relación terapéutica y, en especial, el psicoanálisis no marcha sin esto, es que podemos trabajar caso a caso y librar el rechazado en el campo psicopatológico.

\section{Consideraciones finales}

Las nuevas aportaciones en el campo de salud mental, sostenidas por el NIMH, determinan que el proyecto de la psicopatología debe de estar pautado por evidencias biológicas. Esta concepción, con la finalidad de reducir el mental al orgánico, generó un gran malestar en el campo de la psicopatología, y conllevó un antiguo debate ético, político y científico. En el transcurso de este artículo levantamos y discutimos algunas cuestiones que se renovarán con las últimas declaraciones del NIMH que respaldan la biologización del sufrimiento psíquico humano. Con esto no tuvimos la pretensión de cerrar el debate, sino de reabrirlo, trayendo nuevas informaciones y actualizando el campo.

Para concluir, solemos decir que además del reduccionismo al empirismo del comportamiento que ya teníamos con el DSM, vamos a ver cada vez más un alejamiento entre los investigadores científicos y la clínica en psicopatología. La práctica clínica cotidiana ya no es más una referencia para el tratamiento, no le importa por qué alguien sufre, cómo sufre y cómo maneja su sufrimiento. Esto no es necesario saberlo. La precisión está en la sangre, en las neuroimágenes, en los marcadores biológicos, estos sí son irrefutables.

Eso es el sueño de la psiquiatría moderna, sueño delirante decimos nosotros. Sin embargo, es un delirio colectivo, sostenido por la más importante institución mundial de investigación en salud mental, que tiene como fundamento la ideología de supresión del sujeto. Dicha ideología está basada en la idea de que todo se puede explicar por los marcadores biológicos, es una creencia, así como la creencia religiosa. La ciencia está sustituyendo la religión. Se busca el deus-neurotransmisor, el deus-gen, el deus-neuroimágenes en el campo de la psicopatología.

El psicoanálisis no está ajeno a este debate, pues el sujeto del inconsciente sobreviene por la exclusión del sujeto del campo de la ciencia, supresión que funda el campo del psicoanálisis. Igualmente, como dijo Lacan (1929/1974), el psicoanálisis es un síntoma que desvela el malestar en la civilización. Con eso el psicoanálisis se ocupa de lo que no va bien a través de las palabras. De este modo, no podemos dejar de escucharlas y dar una respuesta aún más al respecto del malestar en la psicopatología contemporánea.

Además, la humanidad no avanza sin lenguaje, por lo tanto, no podemos dispensar la palabra del paciente, ni del científico o del psicoanalista en ese debate. A lo mejor, seguimos con la discusión y con las palabras de Freud (1926/1974) quien dijo: "En si toda la ciencia es unilateral. Tiene que ser asimismo, pues se ha visto que ella se restringe a asuntos, puntos de vista y métodos específicos. Es una insensatez . . . lanzar una ciencia contra otra”. (p. 262)

\title{
The malaise in the contemporary psychopathology
}

\begin{abstract}
The objective of this article is to present an interpretation, oriented by psychoanalysis, about malaise in the field of contemporary psychopathology. Finding biomarkers to explain human behavior and its deviations is a dream long mitigated by psychiatry that now receives new investment from the new strategic plan of the National Institute of Mental Health (NIMH), that on one hand encourages the advancement of science, but on the other poses an organicist reductionism. Without taking the opposite position, that is, of a psychologism of mental disorders or denial of biological factors in psychopathology, this text discusses this topic indicating a clinical, ethical, and epistemological position in approaching mental suffering. We conclude with a contribution of psychoanalysis to the field of psychopathology and mental health practice.
\end{abstract}

Keywords: psychopathology, psychiatry, psychoanalysis and organicism.

\section{Le malaise dans la psychopathologie contemporaine}

Resumé: Le but de cet article est de présenter une lecture orientée par la psychanalyse sur le mal-être dans le domaine de la psychopathologie contemporaine. Trouver des biomarqueurs pour expliquer le comportement humain et ses déviations est un vieux rêve de la psychiatrie, qui gagne maintenant des nouveaux investissements dans le nouveau plan stratégique de National Institute of Mental Heallth (NIMH), lequel, si d'une part encourage le progrès de la science, de l'autre pose un réductionnisme organiciste. Sans prendre le point de vue contraire, soit la position de psychologisme sur des troubles mentaux ou de déni des facteurs biologiques en psychopathologie, on fait la discussion sur le topique en signalant une position clinique, éthique et épistémologique dans le rapport de la souffrance physique. En conclusion, on contribue à la psychanalyse dans le champ de la psychopathologie et de la pratique de la santé mentale.

Mots Clés: psychopathologie, psychiatrie, psychanalyse et organicisme. 


\section{O mal-estar na psicopatologia contemporânea}

Resumo: O objetivo deste artigo é apresentar uma leitura, orientada pela psicanálise, sobre o mal-estar no campo da psicopatologia contemporânea. Encontrar os marcadores biológicos para explicar o comportamento humano e seus desvios é um sonho há muito tempo mitigado pela psiquiatria. E agora ganhou novo investimento a partir do novo plano estratégico do Instituto Nacional de Saúde Mental (NIMH, sua sigla em inglês), que se por um lado estimula o avanço da ciência, por outro, representa um reducionismo organicista. Sem tomar uma posição oposta, ou seja, de um psicologismo dos transtornos mentais ou de uma negação de fatores biológicos em psicopatologia, neste texto discutimos sobre este tema marcando uma posição clínica, ética e epistemológica na abordagem do sofrimento psíquico. Concluímos com uma contribuição da psicanálise para o campo da psicopatologia e da prática em saúde mental.

Palavras-chave: psicopatologia, psiquiatria, psicanálise e organicismo.

\section{Referencias}

Banzato, C. E. M. (2004). Classification in psychiatry: The move towards ICD-11 and DSM-V. Current Opinion in Psychiatry, 17(6), 497-501. Document ID: 739445571.

Banzato, C. E. M. (2009). Deflating psychiatric classification. Philosophy, Psychiatry, \& Psychology, 16, 23-27.

Costa, A. L. L., \& Jardim, L. L. (2003). O corpo e a direção da cura. Revista da Associação Psicanalítica de Porto Alegre, 25, 67-75.

Cuthbert, B. N. (2014). El modelo RDoC: facilitación de la transición del sistema ICD/DSM a los enfoques dimensionales que Integran neurociencia y psicopatología. World Psychiatry, 13(1), 28-35.

Foucault, M. (2001). El nacimiento de la clínica. Una arqueología de la mirada médica. México, DF: Siglo XXI. (Texto original publicado em 1963)

Freud, S. (1974). A questão da análise leiga. In Edição standard brasileira das obras psicológicas completas de Sigmund Freud. Rio de Janeiro, RJ: Imago. (Texto original publicado em 1926)

Freud, S. (1974). O mal-estar na civilização. In Edição standard brasileira das obras psicológicas completas de Sigmund Freud. Rio de Janeiro, RJ: Imago. (Texto original publicado em 1929)

Insel, T. (2013, Abril 29). Transforming diagnosis. Recuperado de www.nimh.nih.gov/transformingdiagnosis.shtml

Jerusalinsky, A., \& Laznick, M. C. (2011). Uma discussão com a neurociência. In A. Jerusalinsky, \& S. Fendrik (Orgs.), O livro negro da psicopatologia contemporânea. São Paulo, SP: Via Lettera.
Lacan, J. (1967). Petit discours de Jacques Lacan aux psychiatres. In El Cercle Psychiatrique Henri Ey, Sainte Anne, el 10 de noviembre de 1967. Recuperado de http:// www.ecole-lacanienne.net/

Lacan, J. (1988). O seminário. Livro 3: As psicoses. Rio de Janeiro, RJ: Jorge Zahar. (Texto original publicado em 1955-1956)

Lacan, J. (1993). Psicoanálisis: radiofonía \& televisión. Barcelona: Anagrama.

Lacan, J. (1998). A direção do tratamento e os princípios de seu poder. In Escritos. Rio de Janeiro, RJ: Jorge Zahar. (Texto original publicado em 1958)

Maj, M. (2014). Keeping an open attitude towards the RDoC project [Editorial]. World Psychiatry, 13(1),1-3.

Pereira, M. E. C. (2009). Bayle e a descrição da aracnoidite crônica na paralisia geral: sobre as origens da psiquiatria biológica na França. Rev. Latinoam. Psicopatol. Fundam., 12(4), 743-751. ISSN 1415-4714.

Rojas Hernandez, M. C., \& Loss Jardim, L. (2007). Algunas puntualizaciones acerca de la ciencia y el cuerpo. Revista Latinoamericana de Psicopatologia Fundamental, 10(1), 6-14.

Zorzanelli, R., Dalgalarrondo, P., \& Banzato, C. E. M. (2014, junio). O projeto Research Domain Criteria e o abandono da tradição psicopatológica. Revista Latinoamericana de Psicopatologia Fundamental, 17(2), 328-341.
Recebido: $13 / 01 / 2015$

Revisado: 23/03/2015

Aprovado: 04/09/2015 